\title{
EFEITOS DE BUTRALIN SOBRE A BROTAÇÃO AXILAR NA CULTURA DE FUMO (Nicotiana tabacum L.)
}

\author{
J.I. FAHL*; A.J.D'A. PINTO** \& A.A. VEIGA*** \\ * Seção de Fisiologia. \\ ** Seção de Plantas Aromáticas e Fumo. \\ *** Estação Experimental de Tietê. \\ Instituto Agronômico de Campinas C.P. 28, \\ 13100 - Campinas - SP \\ Trabalho apresentado na 7.a Reunion e $2 .^{\circ}$ \\ Simpósio Latino Americano de Fisiologia Ve- \\ getal, Mar del Plata - Argentina, 1978. \\ Recebido para publicação em 30.10.79.
}

\section{RESUMO}

Com o objetivo de controlar a brotacão axilar em plantas de fumo e verificar sua influência na produção e característica das folhas, foram estudados, em condições de campo, os efeitos da desbrota manual e de butralin [4-(1,1dimetiletil) - N - (1 metilpropil) - 2,6 dinitrobenzenamina], aplicado diretamente nas gemas axilares ou na extremidade superior da haste em plantas que tiveram removida a inflorescência principal.

Os tratamentos com butralin, independente da maneira de aplicação, proporcionaram completa inibição do crescimento dos brotos axilares, enquanto que a desbrota manual reduziu em $45 \%$ a matéria seca de brotos em relação à testemunha não desbrotada.

Tanto as plantas tratadas com butralin, como as que foram desbrotadas manualmente, não diferiram entre si, quanto ao peso de matéria fresca e, seca de folhas, área foliar especifica e Indice de Área Foliar, porém aumentaram significativamente esses parâmetros em relação ao controle.

UNITERMOS: butralin, fumo, controle da brotação axilar.

\section{SUMMARY}

EFFECTS OF BUTRALIN ON SUCKER CONTROL AND YIELD IN TOBACCO (Nicotiana tabacum L.).

The effects of hand suckering and application of butralin [4 - (1,1 - dimethyl $)-\mathrm{N}-(1-$ methylpropyl) - 2,6 - dinitrobenzenamine] on sucker control, yield and leaf characteristics on tobacco was studied in field conditions. Butralin was applied directly on suckers or on the tops, at 7.000 ppm in water, on plants with removed tops.

Butralin caused complete sucker control with both modes of application. Hand suckering reduced dry matter weight of suckers in $45 \%$ compared to untreated check.

Fresh and dry weight, specific leaf area and leaf area index were not significantly different for chemical and hand suckered plants, but these values were significantly higher, in both cases, when compared to untreated check.

KEYWORDS: butralin, tobacco and sucker control.

\section{INTRODUÇÃO}

A prática de retirar a inflorescência principal e a brotação axilar, na cultura de fumo, é realizada com a finalidade de se obter maior producão, unilidade das suas folhas.

A remoç̃o da inflorescência principal é feita logo após o aparecimento das primeiras flores abertas, e a eliminaçâo dos brotos axilares, em número de duas a quatro, são realizadas no período compreendido entre a retirada da inflorescência principal e a colheita.

Com a escassês de mão-de-obra e o alto custo requerido pela prática da químicos para controlar a brotação vem assumindo grande importância para a cultura de fumo.

Atkinson e Link (1) estudaram os efeitos de vários óleos emulsionáveis à base de petróleo, em plantas de fumo, formidade na maturação e melhor quadesbrota manual, o uso de produtos 
para controlar os brotos, fazendo aplicação na parte superior da haste, a fim de atingir as gemas axilares. Entretanto, devido às injúrias causadas nas mesmas e nas folhas pelos respingos, os resultados desses produtos não foram inteiramente satisfatórios.

Tso (7) verificou que emulsões de metil ésteres de ácidos graxos de cadeias longas (8 a 12 átomos de carbono) poderiam ser aplicados por pulverizações para controlar a brotação, sem, contudo, injuriar as folhas.

Wolfe (8) mostrou que diversas formulações de hidrazida maleica, 1-Decanol e Off-Shoot-T (mistura de álcoois graxos), proporcionaram bom controle na brotação. Nenhum desses produtos causou aumento significativo na produção, mas obteve-se folhas de melhor qualidade para o tratamento com OffShoot-T.

Steffens et al. (5) comparando os efeitos do controle manual e químico da brotação, empregando metif caprato, de açã̉o de contato, e hidrazida maleica, de ação sistêmica, verificaram que esses produtos reduziram o número de brotos por plantas em relação à desbrota manual e que a produção do tratamento com hidrazida maleica foi significativamente maior que a desbrota manual, estando o de metil caprato entre os dois anteriores, sem diferir de ambos.

Collins et al. (2) obtiveram maior grau de controle de brotos, maior produção de folhas e valor por hectare, quando o álcool graxo foi aplicado no estádio em que a inflorescência principal apresentava as primeiras flores abertas, seguido pela aplicação de hidrazida maleica, após 7 a 10 dias. Menor produção e valor por hectare foram obtidos com duas aplicações do produto de ação de contacto.

Mylonas e Pango (3), estudando os efeitos dos produtos: n-Decanol, pendimethalin, butralin e Off-Shoot-T, verificaram que todos os tratamentos reduziram o peso e o número de brotos por planta em relação à testemunha não desbrotada, elevando a produção e a qualidade das folhas. Os tratamentos com retirada da inflorescência principal, tanto com desbrota manual como aplicação de produtos químicos, apresentaram maior produçăo e valor por hectare em relação às testemunhas.

Schipfer e Hofer (4) verificaram que, entre diversos produtos testados, os melhores resultados foram obtidos pelos tratamentos com Off-Shoot-T e pela mistura de 9\% de butralin e 54\% de álcool (C8 e C10).

$\mathrm{O}$ presente trabalho foi realizado com o objetivo de verificar os efeitos da desbrota manual e o uso de butralin, aplicado diretamente nas gemas axilares ou na parte superior da haste, no controle da brotação axilar, da produção e das características das folhas na cultura de fumo.

\section{MATERIAL E MÉTODOS}

O trabalho foi conduzido na E.E. de Tietê, do InstItuto Agronômico, em uma cultura da cultivar IAC-70 Goiano, específico para produção de fumo de corda, cultivado no espaçamento de $1,20 \mathrm{~m}$ por $0,60 \mathrm{~m}$.

O delineamento foi de blocos ao acaso, com 4 tratamentos e 5 repetições, tendo cada parcela $6,0 \mathrm{~m}$ por $1,20 \mathrm{~m}$, com 10 plantas úteis, separadas por bordadura de três plantas na linha. Os tratamentos foram iniciados em 12 de junho de 1978, após a retirada da inflorescência principal, no estádio em que esta apresentava as primeiras flores abertas, constando de: 1) Testemunha: crescimento livre dos brotos axilares; 2) Desbrota manual: retirada manual dos brotos axilares; 3) Pulverização com butralin $(7.000 \mathrm{ppm})$ diretamente nas gemas axilares das folhas e, 4) Pulverização com butralin (7.000 ppm) na extremidade superior da haste.

No tratamento número 3 , a solução de butralin em água foi aplicada diretamente nas gemas axilares, utilizando-se um pulverizador manual de gatilho tomando o cuidado para que todas as gemas fossem pulverizadas. No número 4 , utilizouse um pulverizador do tipo costal, manual, com barra curva, e uma boquilha ao bico, para que a solução pulverizada na extremidade superior da haste atingisse uniformemente todas as gemas. Foram gastos, nestes tratamentos, aproximadamente 15 $\mathrm{ml}$ e $20 \mathrm{ml}$ por planta, respectivamente.

As desbrotas manuais foram realizadas em número de cinco, no período compreendido entre o início dos tratamentos e a colheita das folhas, retirando-se os brotos com comprimento superior a 5 centímetros, os quais eram postos a secar a $70^{\circ} \mathrm{C}$ em estufa com circulação forçada de ar, pesados, e os pesos somados no final.

Os brotos axilares do tratamento não desbrotado, foram retirados na colheita final e postos a secar em estufa nas condições anteriores e pesados.

No final do ciclo vegetativo da planta de fumo, 55 dias após o início dos tratamentos, foram realizadas duas coletas de folhas separadamente: uma retirando-se de cada planta 3 folhas (uma da 
parte inferior, uma mediana e uma superior) e outra das folhas restantes, obtendo-se imediatamente após, o peso da matéria fresca de ambas.

De cada folha da 1.a coleta, foram retirados 5 discos de $18 \mathrm{~cm}^{2}$ e a nervura principal. Os componentes: discos, nervura principal e retalhos da folha foram postos a secar em estufa com circulação forçada de ar e pesados.

Através das relações do peso de matéria fresca total das folhas, peso da matéria seca das folhas da l.a coleta, peso de matéria seca dos discos e área dos mesmos, foram calculados os seguintes parâmetros: 1) Peso de matéria fresca das folhas (g/planta); 2) Peso de matéria seca de folhas (g/planta); 3 ) Area foliar ( $\mathrm{dm}^{2} /$ planta); 4) Area foliar especifica $\left(\mathrm{g} / \mathrm{dm}^{2}\right)$ calculada pela relação peso de matéria seca dos discos pela sua área e 5) Índice de área foliar.

\section{RESULTADOS E DISCUSSÃO}

Pelo quadro 1 , pode ser observado que ambos os tratamentos com butralin, tanto o pulverizado diretamente nas gemas axilares das folhas, como $o$ pulverizado na parte superior da haste, proporcionaram controle de $100 \%$ da brotação, inibindo totalmente o crescimento e desenvolvimento do meristema das gemas axilares, até a coleta das folhas. Esse efeito inibitório, provocado por dinitroanilinas, na divisão celular de tecido meristemático, foi também verificada por Talbert (6) em raízes de soja.

No tratamento em que o controle da brotação foi realizado manualmente, houve redução de $45 \%$ no peso de maté ria seca de brotos comparado à testemunha não desbrotada.

$\mathrm{O}$ quadro 2 mostra os efeitos do controle manual e do butralin sobre as características morfológicas das folhas. Tanto o controle manual da brotação como o químico, proporcionaram aumentos significativos em todos os parâmetros estudados, quando comparados à testemunha não desbrotada.

Não houve diferenças significativas, com relação aos parâmetros estudados, entre o tratamento que teve a brotação controlada manualmente e os controlados com butralin, os quais também não diferiram entre si, evidenciando que o butralin, além de mostrar-se eficiente no controle da brotação, não causou nenhum efeito prejudicial ao crescimento normal das folhas.

O aumento no peso da matéria seca das folhas dos tratamentos que tiveram os brotos controlados manual ou quimicamente, ocasionado pelo aumento da área das folhas e da área foliar específica, deve ser devido ao aumento do índice de área foliar, que possibilitou maior superfície fotossiatetizante e à pouca ou nenhuma competição de nutrientes exercida pelos brotos.

Os resultados obtidos quanto ao aumento na produção de matéria fresca das folhas, proporcionado pelos tratamentos com butralin em relação à testemunha não desbrotada, concorda in-

Quadro 1 - Efeitos de butralin e da desbrota manual sobre a produção de matéria seca de brotos axilares em cultura de fumo (Nicotiana tabacum L.). Médias de 5 repetições.

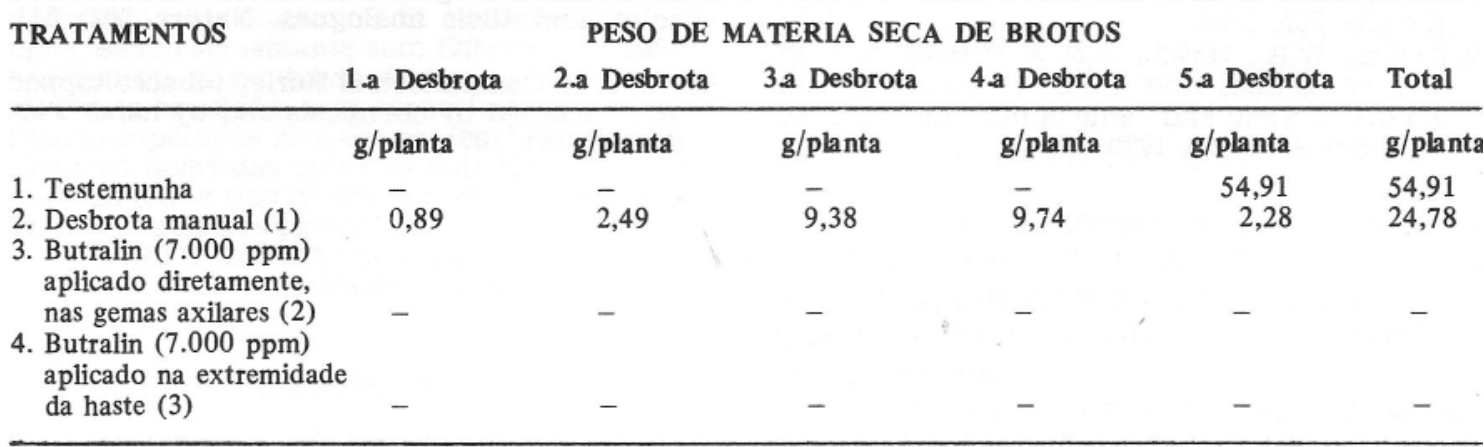

(1) - remoção manual de brotos com comprimento superior a $5 \mathrm{~cm}$, após retirada da inflorescência principal.

(2) - pulverização de butralin $(7.000 \mathrm{ppm})$, após a retirada da inflorescência principal, diretamente nas gemas axilare

(3) - pulverização com butralin $(7.000 \mathrm{ppm})$, após a retirada da inflorescência principal, na extremidade superior da haste atingindo as gemas axilares uniformemente. 
Quadro 2 - Efeitos de butralin e da desbrota manual sobre peso de matéria fresca e seca de folhas, área foliar específica, área foliar por planta e indice de área foliar em cultura de fumo (Nicotiana tabacum L.). Médias de cinco repetiçóes.

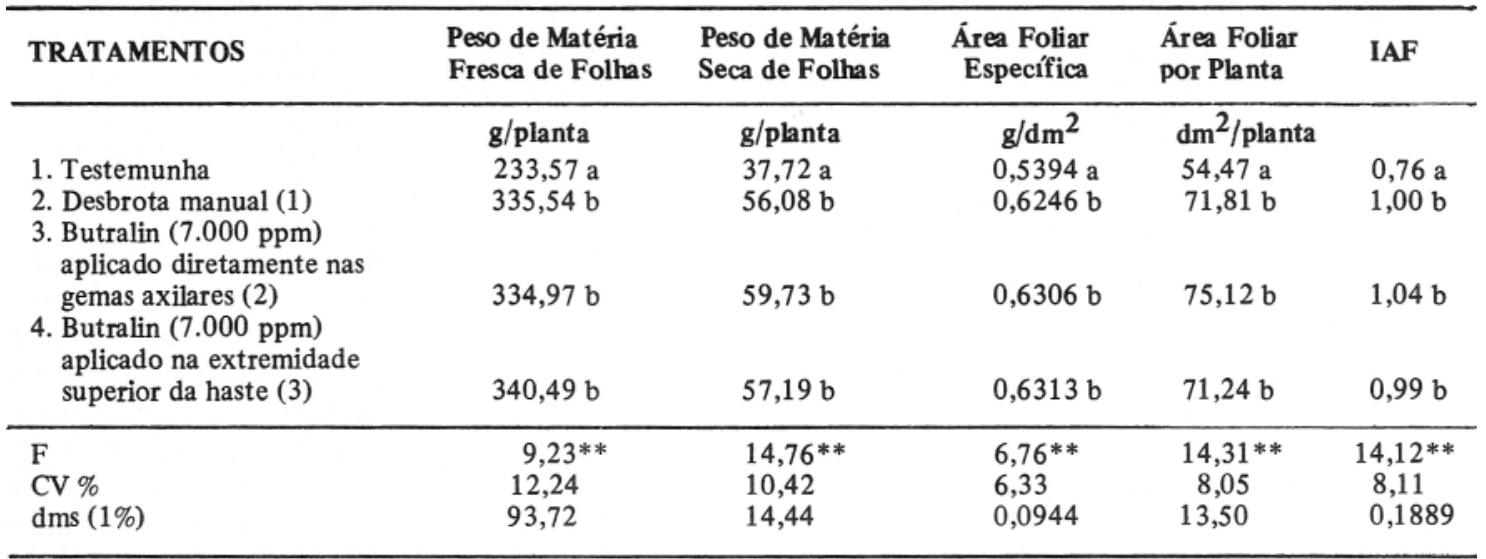

(1) - remoção manual de brotos com comprimento superior a $5 \mathrm{~cm}$, após retirada da inflorescência principal.

(2) - pulverização de butralin $(7.000 \mathrm{ppm})$, após a retirada da inflorescência principal, diretamente nas gemas axilares

(3) - pulverização com butralin $(7.000 \mathrm{ppm})$, após a retirada da inflorescência principal, na extremidade superior da haste, atingindo as gemas axilares uniformemente.

teiramente com os dados obtidos por Mylonas e Pango (3).

Esses resultados mostram que a brotação de plantas de fumo pode ser controlada com aplicação de solução de butralin através de pulverização dỉrigida à parte superior da haste da planta, logo após a retirada da inflorescência principal, quando esta apresentar as primeiras flores abertas.

\section{LITERATURA CITADA}

1.Atkinson, W.O. \& Link, L. Use of sucker control materials on Burley and dark tobacco. Univ. of Ky. Cir. 556, 1958.

2.Collins, W.K.; Hawks, S.N. \& Kittrell, B.V. Effect of contact and systemic sucker control agents on yield and value of fluecured tobacco. Tob. Sci. 14: 65-68. 1970.
3. Mylonas, V.A. \& Pangos, E.A. Effects of chemical agents on sucker control and certain agronomic and chemical characteristics in Burley tobacco.

Tob. Sci. 22: 85-88, 1978.

4. Schipfer, L. \& Hofer, F. Chemical treatments of tobacco plants. Coresta Inf. Bull. Montreux Symp. 109-110, 1974.

5. Steffens, G.L.; Spauding, D.W.; Atkinson, W.O.; Bortner, C.E.; Link, L.A.; Nichols, B.C.; Ross, H.F.; Heinz Seltmann \& Luter Shaw. Regional test with contact and systemic tobacco sucker control agents. II. Burley tobacco. Tob. Sci. 13: 117-120,1969.

6. Talbert, R.E. Effects of trifluralin on soybean root development. Proc. 18th Southern Weed Control. Conf. p.652, 1965.

7. Tso, T.C. Plant growth inhibition of some fatty acids and their analogues. Nature 202: 511, 1964.

8. Wolfe, R. Comparison of Burley tobacco topped and suckered by chemicals and by hand. Tob. Sci. 15: 151. 1971. 